\title{
Chinese Rule-Abiding Decision-Making and Hidden Motives: Simulation Findings and Implications
}

\author{
Mingyue Wen \\ School of Government, Nanjing University, Nanjing, China \\ Email: mingyuewen@hotmail.com
}

How to cite this paper: Wen, M. Y. (2018). Chinese Rule-Abiding Decision-Making and Hidden Motives: Simulation Findings and Implications. Advances in Applied Sociology, 8, 95-105.

https://doi.org/10.4236/aasoci.2018.82006

Received: January 8, 2018

Accepted: February 4, 2018

Published: February 7, 2018

Copyright $\odot 2018$ by author and Scientific Research Publishing Inc. This work is licensed under the Creative Commons Attribution International License (CC BY 4.0).

http://creativecommons.org/licenses/by/4.0/

\section{c) (i) Open Access}

\begin{abstract}
In order to understand how hidden motives operate in organized social systems in China, I conducted a laboratory experiment to answer three research questions as follows: Are Chinese citizens generally and state cadres (non-manual workers on government payroll) in particular rule-abiding beings? What are their underlying motives when making rule-abiding decisions? What are the sociological and political implications that can be drawn from their rule-abiding decision-making regularities? The findings form a basis to yield answers for future verification. First, the subjects were rule-abiding beings observing both formal and informal rules. Second, given the interventions, the subjects' decision-making reflected that they had different motives when making rule-abiding decisions, following the collective-interest-oriented logic of consequentialism, the logic of appropriateness, the self-interest-maximization logic of consequentialism, the logic of appropriateness, and the logic of practicality. And third, given that most subjects could be considered pragmatic-rational beings, the ground for building socialism is sociologically and politically shaky. The CPC leadership has to be more devoted to searching for contemporary social and political ideologies to displace the prevailing pragmatic-rational values.
\end{abstract}

\section{Keywords}

China, Decision-Making Motive, Laboratory Experiment, Organized Social Systems, Rule-Abiding Decision-Making

\section{Introduction}

In all organized social systems, be they nations, governments, institutions, or 
enterprises, man-made formal rules govern the individual and collective behaviors of their members (Barzelay \& Gallego, 2006). Such macro-level neo-institutional theories (Goldmann, 2005) and messo-level public choice theories (Ostrom, 1998) offer plausible explanations to account for the regularities of rule-abiding behaviors. When rules are changed, behaviors change as well. But the scope and magnitude of behavioral change may differ among members of the same organized social system. Eventual behavioral changes could also be drastic, which is hardly unusual, as according to the chaos theory, even small changes of the parameters may induce drastic changes (Overman, 1996). Macro- and messo-level theories, however, could not explain or predict the actual behavioral changes of members of the organized social systems, because the behavioral change is induced by individual members' hidden motives.

In contrast, organizational psychologists have made substantial contributions to our enhancement of the understanding of how micro-level hidden motives operate in organized social systems in the West. Take Vroom's (2007) expectancy theory as an example. This rational calculation theory focuses on the inter-relationships among expectancy, instrumentality, and valence to explain and predict that members of an organized social system (be they blue-collar workers, managers, or professionals) can be motivated towards performance objectives if they recognize that a positive correlation between efforts and performance does exist and that the enhancement of the prescribed performance will result in a specific reward, which would satisfy a need meaningful to the performer. This rational calculation theory and other social psychological force theories, such as the achievement motivation theory (McClelland, 1961) and public service motivation theory (Perry \& Wise, 1990), are pertinent to understanding, explaining, and predicting the formation, processes, and effects of micro-level motivational forces. Similar research in developing countries, however, has been meager. As such, I conducted such a needed research in the past nine years to yield findings essential to understanding how hidden motives operate in organized social systems in China. In specific, my research questions were as follows: Are Chinese citizens generally and state cadres (non-manual workers on government payroll) in particular rule-abiding beings? What are their underlying motives when making rule-abiding decisions? What are the sociological and political implications that can be drawn from their rule-abiding decision-making regularities?

To address these questions, I had conducted in 2008 one laboratory experiment that involved 160 subjects. I did not try to deduce hypotheses from motivation theories for testing, and did not merely use that single laboratory experiment to establish conclusive findings. Instead, I also used longitudinal interview (2008-2016) to temporally cross-check the initial findings. These research design decisions were based on related research findings. In brief, social scientists have highlighted the various shortcomings of neo-positivism (e.g., Raadschelders, 2011; Whetsell \& Shields, 2015) and underlined the deficiencies of applying mono-framework and mono-method (e.g., Druckman et al., 2006; Heinrich, 
2007). More important, researchers have documented the practicality and values of applying inter-epistemological approaches (e.g., Hummel, 2011; Ketokivi \& Mantere, 2010), methodological pluralism (McGinnis \& Ostrom, 2011), and multiple-level analysis (Perry, 2012).

Based on the above, I tried to effectuate my quest for a more complete account of causal relationships of the subjects' rule-abiding behavioral tendencies and hidden motives, which I considered indispensable to forming a social scientific knowledge base for explaining and even predicting the occurrence of rule-abiding decision-making events in China. Further, I chose to employ the scientific empiricist foundationalism approach (Kilduf, Mehraand, \& Dunn, 2011) to guide the designing of my study and to focus on meaningful interpretation of findings generated from the laboratory experiment and longitudinal interview. The details are as follows.

\section{The Laboratory Experiment and Longitudinal Interview}

Underlying the motives of rule-abiding decision-making of state cadres and citizens is a pre-theoretical pursuit, which would eventually facilitate explanatory and/or predictive analysis basing on the clarification of causal relationships and identification of necessary and sufficient conditions for event occurrence. Such methods as document analysis, field observation, and elite interview being popularly used by sinologists are essential to understanding general political development, but could not reveal the basic regularities of decision-making of state cadres and citizens, of which are difficult to detect but easy to conceal. A methodological alternative is human-assisted simulation, which is one form of laboratory experiment. It has been used in political and administrative studies in the US (Bozeman \& Scott, 1992; Druckman et al., 2006; Jilke, Van de Walle, \& Kim, 2017) to enhance theoretical breakthrough. Indeed, Nobel Laureate Elinor Ostrom had effectively conducted many human-assisted simulations to generate plentiful empirical findings indispensable to the articulation of the second generation public choice theory (McGinnis \& Ostrom, 2011; Ostrom, 1998).

I therefore considered it necessary to conduct human-assisted simulation so as to generate empirical evidence about the rule-abiding behavioral tendencies of Chinese state cadres and citizens. More important, I was with the conviction that longitudinal interviews should also be conducted after the simulation for the aforementioned rationales as suggested in the literature in order to reveal the sustaining underlying logic of decision-making. Thus, I conducted the longitudinal interviews in 2012-2016.

In brief, I conducted in October 2008 a laboratory experiment using humanassisted simulation to explore the decision-making logics of state cadres and citizens. A total of 160 Chengdu residents participated on voluntary basis. These subjects were state cadres (40 persons; $25 \%$ ), other citizens from all walks of life (40 persons; 25\%), and undergraduate students of Sichuan University (40 persons; 50\%; an additional 40 students participated in the pilot study). These sub- 
jects were not randomly selected due to their voluntary signing up. In specific, I set a quota for each category (i.e., 40 for state cadres; 40 for Chengdu residents; 80 for undergraduate students). After the voluntary signing up meeting the quotas, I sent out invitations to the volunteers to participate in the experiment.

The experiment was conducted in Sichuan University and repeated four times, with 40 subjects participated in each simulation. The first simulation was a pilot study with 40 undergraduate students serving as the subjects. The main purpose was to generate useful information for refining the procedures. Afterwards, the second simulation (a control group study) that involved 40 state cadres and ordinary citizens was conducted. In it, the procedures were similar but without intervention. The third and fourth simulations were conducted with interventions. Forty cadres and citizens as subjects participated in the third simulation, while 40 undergraduates participated in the fourth simulation.

In order to clarify the subjects' underlying logics of decision-making, postsimulation interviews at the spot were conducted to ascertain their decisionmaking rationales. In addition, longitudinal interviews with the subjects of the third and fourth simulations were also conducted-at a three-year interval after the simulation (December 2011 and January 2015) to tap the subjects' sustaining logic of decision-making. Individual interviews with subjects who still resided in Chengdu in 2017 were also conducted. Information so collected was used to tap changes in their decision-making logics. All these three rounds of longitudinal interviews had documented that the subjects' basic preferential tendencies as revealed in the simulation were rather stable, notwithstanding changes in time and enrichment of sociopolitical experiences.

The specific simulation procedures were as follows: The subjects were placed in a hypothetical decision-making situation involving a newly built 255 -acre office complex for sale. They were briefed that the office complex was meant to be the new headquarters of the Chengdu Municipality but, in view of the disastrous Wenchuan earthquake (12 May 2008), the State Council considered it appropriate to sell it to raise relief fund. The subjects were further told that a prospective purchaser had made an offer of 1.2 billion RMB, which was substantially below the building cost ( 2.5 billion RMB). The administrative leadership had thus decided to set up an expert panel to price the office complex, with the options being the market price (2.9 billion RMB), discounted price ( 2 billion RMB), and offered price (1.2 billion RMB).

In the simulation, the expert panel was composed of 48 persons -8 panel experts, as well as the chairperson, vice-chair, and secretary of the panel, were confederates. Three interventions were made in the first, third, and fourth simulations. Firstly, a Background Paper containing information about the sales and purchase negotiation was given to the subjects. In it, $50 \%$ of the subjects received written instruction from senior municipal administrators to endorse the offered price-this intervention was made to find out if the subjects were submissive to administrative authority. The subjects were then asked to vote on the sale price 
by ballot.

Secondly, the panel secretary "counted" the votes and then announced a tie (disregarding the actual voting). The panel chair "showed" dissatisfaction and then summoned the 8 confederates to give voting instruction. They then approached the subjects ( 5 subjects per confederate) to inform them that the Chengdu Party Secretary actually did not want to sell the office complex and thus had instructed the panel chair to ensure that the expert panel would vote for the market price in order to reject the offer-this intervention was made to find out if the subjects would change their vote to comply with request from political authority. Afterwards, the subjects were to vote for the second time.

And thirdly, a (falsified) tie was again announced. The panel vice-chair then reminded the secretary to inform the panel that the government had arranged to pay each participant $5000 \mathrm{RMB}$ as an expert fee for attending the meeting. The arrangement was that each panel could only vote three times. If unresolved, a next panel meeting would be organized with the same panel fee paid, but if still unresolved, the panel would be dissolved. This intervention was made to find out if the subjects would strive to advance their own interests by disregarding administrative and political influences. After the voting, I concluded the simulation.

Debriefing was made, and post-simulation interviews with the subjects were conducted. In brief, the post-simulation interviews, as well as the longitudinal interviews, were semi-structured. The guiding rule I adopted in the post-simulation and longitudinal interviews was value-free questioning so as to avoid creating stress or uneasiness for the subjects, who otherwise would not speak frankly. The lead question was "Can you share with me the rationales of your decision-making?" Depending on the uniqueness of the subjects' answers, follow-up questions that revolved around the motives behind the subjects' decision-making were posed. For example, when respective subjects had responded to the intervention of selfinterest serving, the follow-up question was "How did you reason when you decided to deviate from your original decision?”

\section{The Key Findings}

The six key findings of the laboratory experiment are as follows. First, the voting record of the first simulation (i.e., the pilot study involving undergraduates) showed remarkable consistency in the cohort's three sets of voting-mostly choosing the market price option; deviation was rare. The post-simulation interviews showed that most of them deemed the discounted price reasonable in light of the negative impacts on Chengdu's economy generated by the Wenchuan earthquake, and therefore voted accordingly, notwithstanding the interventions. In short, these undergraduates could be classified as responsible beings committed to making rational decisions for optimal outcome. Their decision-making motive can be classified as the collective-interest-oriented logic of consequentialism (Hopf, 2010; March \& Olsen, 1998; Ostrom, 1998) - that is, the subjects had the motive to make decisions that generated optimal benefits for all stake- 
holders, and thus had reasoned to rationally calculate the benefit and cost involved. Basing on this logic, they disregarded administrative directive, political influence, and monetary seduction.

Second, the record of the second simulation involving the control group showed that the subjects had voted in a consistent manner. At the absence of political pressure and monetary seduction, the control group primarily voted for the discount option. The post-simulation interviews showed that the subjects analyzed and concluded in the same way as their counterparts of the pilot study did. The decision-making behavior of these subjects (cadres and citizens) reflected that, at the absence of administrative pressure, political influence, and monetary seduction, they were quite capable of making sensible decision. The post-simulation interviews also documented that they, basing on the collectiveinterest-oriented logic of consequentialism, did hold themselves responsible for making sound judgment for society.

Third, given the administrative and political interventions, all subjects of the third and fourth simulations had voted according to administrative instruction and political directive in the first and second round. They admitted in the postsimulation interviews that they felt uncomfortable to vote against the preferences of the authority. In other words, be they undergraduates, citizens, or cadres, the subjects showed a strong tendency to submit to authority, reflecting that their decision-making was based on the logic of appropriateness (Hopf, 2010; March \& Olsen, 1998) conditioned by political influences.

Fourth, the voting record also showed that the subjects' submission to authority was hardly unconditional-when their personal gain was at stake, they would vote differently. In specific, $35 \%$ of the subjects (28 persons) deviated from their precedent voting after the announcement of the per diem policy. The post-simulation interviews indicated that these subjects had intentionally chosen the price option that had received the least votes in the second set of voting so as to manipulate the final voting outcome. This means that one-third of the subjects were economic-rational beings, who made decisions basing on the logic of appropriateness and the self-interest-maximization logic of consequentialism (Ostrom, 1998). It should be noted their decision-making logic and actual voting behavior were mediated by a critical factor, namely, anonymity. They were asked in the post-simulation interview whether or not they would vote in the same way if hand-show was to be used. Almost all indicated their unwillingness to expose their self-serving preference. The implications are obvious: First, these subjects were risk-aversive rational actors capable of analyzing the action context to optimize positive outcome or minimize negative effect; and second, their actual decisions were made basing on the logic of practicality (Pouliot, 2008).

Fifth, nearly two-third of the subjects ( 52 persons) did not change their voting preference. Seemingly, they had disregarded monetary seduction. Post-simulation interviews, however, had documented that 15 subjects (19\%) had actually opted to deviate, but then concluded it unnecessary as the outcome of the second vot- 
ing was suggestive enough that a tie in the third round of voting was likely. In other words, these subjects had conducted strategic calculation and were as pragmatic and rational as their economic-rational counterparts. This means 54\% of the subjects could be classified as economic-rational beings, who made decisions basing on the logic of appropriateness and the self-interest-maximization logic of consequentialism. More important, the underlying motives and decisionmaking of these 15 subjects (19\%) were far more sophisticated, involving the logic of appropriateness, self-interest-maximization logic of consequentialism, and the logic of practicality.

And sixth, the background information provided by the subjects showed that gender, age, education, ethnic origin, and occupation did not co-relate with their decision-making behaviors. More important, political affiliation was also unrelated to the subjects' tendency to submit to authority or to advance self-interest, as 58 subjects $(73 \%)$ were either Communist Youth League members or CPC members. This specific finding suggests that CPC supporters were as pragmatic and economic-rational as ordinary citizens, even though they were supposed to be ideologues committed to advancing collective interests.

In sum, the laboratory experiment reported above has found that $54 \%$ of the subjects were pragmatic-rational beings, inferring that the majority of state cadres and citizens in the Chengdu area may be as pragmatic and rational-willing to submit to authority in the current context of political monism but seeking optimality of self-interest when objective conditions permit. In view of the fact that Chengdu's socioeconomic conditions are hardly atypical, one may speculate that cadres and citizens in other parts of China are as pragmatic and rational as their counterparts in Chengdu. Indeed, the field observation and in-depth interview conducted by me in southern China in the past three years have documented that most state cadres are primarily pragmatists concerned with career and personal interest advancement.

\section{Implications}

Regarding sociological implication, the laboratory experiment reported above shows that most cadres and citizens are likely to be pragmatic-rational beings with their preferences and behavioral tendencies basing on rational calculation for personal interest protection or advancement. The field interviews so conducted have documented the same. An inference from these findings is that pragmatism and instrumental rationality are prevailing in China. Internalization of these values by an individual is merely a micro-level phenomenon. When most members of the social system subscribe to these same values, it becomes a macro-level phenomenon with systemic effects. In other words, from the social reality construction perspective (Berger \& Luckman, 1966; Hummel, 1994), an objectified social reality is in formation, making it impossible for individual citizens to renovate the pragmatic-rational society and for CPC to use hereand-now, piece-meal reform measures to alter it. As pragmatism and rationality 
contradict socialist values and communist ideals, the substantive values of CPC governance are marginalized and thus its ruling legitimacy is in erosion. In other words, the prevalence of pragmatic-rational values in PRC has already become a macro-level necessary condition for regime collapse. More importantly, when the values of pragmatism and instrumental rationality prevail, social relationships would become fragile, and social cohesiveness weaken. These means the Chinese society may very well re-transform into "a society of loose sand" as it was before the establishment of the PRC.

Regarding political implication, the research findings together document that most Chinese power wielders are likely to be pragmatic-rational beings. Given their logics of decision-making and behavioral tendencies, they probably would deviate from Party and governmental policies when feasible, practical, and beneficial. They might even reject CPC governance when their well-beings could be better served by other institutional structure and political parties. Further, as Western style democracy could better safeguard individuals' political rights and economic interests, pragmatic-rational cadres and citizens are very likely to endorse regime succession when pro-democracy proposals that better serve their personal interests are tabled. Nevertheless, it should be noted that the necessary condition for the subjects of the simulation to vote according to their pragmatic value was anonymity. This means that cadres and citizens would vote for democratic regime succession only if citizen referendum is used.

I have pointed out in another research report (under review) that the prevailing norm self-serving contradicts the basic values of socialism. A reified social reality of individualism, human greed, irresponsibility, and realpolitik would inevitably compel the Chinese people to reject CPC's governance. The Xi (Jinping) administration (2012-present) has already strived to mount political support by advocating "Chinese dreams" (for details, see, e.g., Heberer, 2014, 2015). The effectiveness, however, has been questionable, as "Chinese dreams" could merely be individuals' dreams of self-enrichment (such as accumulating more wealth or migrating to the USA), which may further reinforce individualism. Seemingly, Western style democratization as forecasted by such China watchers as Gilley (2008) may soon become a reality. Yet, Western style democratization that takes place in a self-serving-oriented behavioral context with defective rule-of-law policy and checks-and-balances mechanisms would intensify realpolitik and eventually lead to political instability and even chaos. The self-serving and corrupt Nationalist regime (1911-1949) documented exactly that. In the $21^{\text {st }}$ Century, a loose-loose outcome for all the Chinese people is likely, unless the aforementioned reified reality can be transformed. Pragmatic reforms are in effect useless, as they could merely delay Western style democratization and subsequent chaos.

\section{Concluding Remarks}

To reiterate, my research questions were as follows: Are Chinese citizens generally and state cadres (non-manual workers on government payroll) in particular 
rule-abiding beings? What are their underlying motives when making rule-abiding decisions? What are the sociological and political implications that can be drawn from their rule-abiding decision-making regularities? The findings reported in the preceding pages form a basis to yield answers for future verification. First, indeed the subjects were rule-abiding beings as they all accepted the formal rules as stipulated in the experiment. Further, most of them also adhered to the informal rules when they received administrative cues and political signals.

Second, given the interventions, the subjects' decision-making reflected that they had different motives when making rule-abiding decisions. Some followed the collective-interest-oriented logic of consequentialism to make decisions that would generate optimal benefits for all stakeholders in society. Some decided basing purely on the logic of appropriateness and the self-interest-maximization logic of consequentialism. Some others would apply the logic of appropriateness, self-interest-maximization logic of consequentialism, and the logic of practicality to make risk-aversive decisions basing on their personal interest's benefit-andcost analysis.

And third, given that most subjects could be considered pragmatic-rational beings, the ground for building socialism is sociologically and politically shaky. The CPC leadership has to be more devoted to searching for contemporary social and political ideologies to displace the prevailing pragmatic-rational values. As some subjects had shown that their underlying motive of decision-making was collective-interest-oriented logic of consequentialism, the CPC leadership should focus on strategies that could help trigger the popularity of this type of decision-making. Scholarly efforts expended may facilitate such a pursuit not only in China but also in other countries troubled by the prevalence of pragmaticrational values.

All in all, while this research had generated relevant findings that shed light on the 160 subjects' underlying motives that triggered rule-abiding decisions and that yielded sociological and political implications for future theoretical studies and policy reformulation, it should be noted that the sample size of the subjects is relatively small, meaning that the subjects may not be representative of the population and that the external validity of the findings may be very limited. Moreover, the underlying motives of rule-abiding decision-making in the real world may be more complex than I have documented in this study. For example, human motives could be manipulated by various social and situational factors in the real world decision-making context, particularly when individuals have competing motives. Furthermore, the simulation was conducted in 2008. Some researchers (Chan \& Chow, 2007; Zheng, 2012) had pointed out that the sociopolitical development in China was quite problematic in the first decade of the $21^{\text {st }}$ Century, as corruption was epidemic and individualism was in prevalence. After the $18^{\text {th }}$ National Congress of CPC (2012), the CPC leadership has undertaken drastic and harsh administrative measures to curb corruption and polit- 
ical actions to neutralize individualism (Zheng, 2013). As such, the real world decision-making context may be in transformation. The regularities of motivational processes and decision-making may have changed as well. Thus, a replication of my simulation study in this new socio-political context would yield findings that shed light on the subtle changes of Chinese people's underlying motives of decision-making.

\section{Funding}

This project (Code: 2016M601780) is funded by the China Postdoctoral Science Foundation.

\section{References}

Barzelay, M., \& Gallego, R. (2006). From "New Institutionalism” to "Institutional Processualism": Advancing Knowledge about Public Management Policy Change. Governance, 4, 531-557. https://doi.org/10.1111/j.1468-0491.2006.00339.x

Berger, P., \& Luckman, T. (1966). The Social Construction of Reality: A Treatise in the Sociology of Knowledge. London: Penguin Books.

Bozeman, B., \& Scott, P. (1992). Laboratory Experiments in Public Policy and Management. Journal of Public Administration Research and Theory, 3, 293-313.

Chan, H. S., \& Chow, K. W. (2007). Public Management and Policy in Western China: Metapolicy, Tacit Knowledge, and Implications. American Review of Public Administration, 4, 479-498. https://doi.org/10.1177/0275074006297552

Druckman, J. N., Green, D. P., Kuklinski, J. H., \& Lupia, A. (2006). The Growth and Development of Experimental Research in Political Science. The American Political Science Review, 4, 627-635. https://doi.org/10.1017/S0003055406062514

Gilley, B. (2008). Legitimacy and Institutional Change: The Case of China. Comparative Political Studies, 3, 259-284. https://doi.org/10.1177/0010414007308020

Goldmann, K. (2005). Appropriateness and Consequences: The Logic of Neo-Institutionalism. Governance, 1, 35-52. https://doi.org/10.1111/j.1468-0491.2004.00265.x

Heberer, T. (2014). China in 2013: The Chinese Dream's Domestic and Foreign Policy Shifts. Asian Survey, 1, 113-128. https://doi.org/10.1525/as.2014.54.1.113

Heberer, T. (2015). China in 2014: Creating a New Power and Security Architecture in Domestic and Foreign Policies. Asian Survey, 1, 82-102. https://doi.org/10.1525/as.2015.55.1.82

Heinrich, C. J. (2007). Evidence-Based Policy and Performance Management: Challenges and Prospects in Two Parallel Movements. The American Review of Public Administration, 3, 255-277. https://doi.org/10.1177/0275074007301957

Hopf, T. (2010). The Logic of Habit in International Relations. European Journal of International Relations, 4, 539-561. https://doi.org/10.1177/1354066110363502

Hummel, R. P. (1994). The Bureaucratic Experience. New York, NY: St. Martin's Press.

Hummel, R. P. (2011). Stories Managers Tell: Why They Are as Valid as Science. Public Administration Review, 1, 31-41.

Jilke, S., Van de Walle, S., \& Kim, S. H. (2017). Generating Usable Knowledge through an Experimental Approach to Public Administration. Public Administration Review, 1, 69-72.

Ketokivi, M., \& Mantere, S. (2010). Two Strategies for Inductive Reasoning in Organiza- 
tional Research. The Academy of Management Review, 2, 315-333. https://doi.org/10.5465/AMR.2010.48463336

Kilduf, M., Mehraand, A., \& Dunn, M. B. (2011). From Blue Sky Research to Problem Solving: A Philosophy of Science Theory of New Knowledge Production. Academy of Management Review, 2, 297-317.

March, J. G., \& Olsen, J. P. (1998). The Institutional Dynamics of International Political Orders. International Organization, 4, 943-969. https://doi.org/10.1162/002081898550699

McClelland, D. C. (1961). The Achieving Society. New York, NY: Free Press.

McGinnis, M. D., \& Ostrom, E. (2011). Reflections on Vincent Ostrom, Public Administration, and Polycentricity. Public Administration Review, 1, 15-25.

Ostrom, E. (1998). A Behavioral Approach to the Rational Choice Theory of Collective Action-Presidential Address. American Political Science Review, 1, 1-22. https://doi.org/10.2307/2585925

Overman, E. S. (1996). The New Sciences of Administration: Chaos and Quantum Theory. Public Administration Review, 5, 487-491. https://doi.org/10.2307/977050

Perry, J. L., \& Wise, L. R. (1990). The Motivational Bases of Public Service. Public Administration Review, 3, 367-373. https://doi.org/10.2307/976618

Perry, J. L. (2012). Editorial: How Can We Improve Our Science to Generate More Usable Knowledge for Public Professionals? Public Administration Review, 4, 479-482.

Pouliot, V. (2008). The Logic of Practicality. International Organization, 2, 257-288.

Raadschelders, J. C. N. (2011). The Future of the Study of Public Administration: Embedding Research Object and Methodology in Epistemology and Ontology. Public Administration Review, 6, 916-924. https://doi.org/10.1111/j.1540-6210.2011.02433.x

Vroom, V. H. (2007). On the Origins of Expectancy. In K. G. Smith, \& M. A. Hitt (Eds.), Great Minds in Management: The Process of Theory Development (pp. 239-259). Oxford: Oxford University Press.

Whetsell, T. A., \& Shields, P. M. (2015). The Dynamics of Positivism in the Study of Public Administration: A Brief Intellectual History and Reappraisal. Administration \& Society, 4, 416-446. https://doi.org/10.1177/0095399713490157

Zheng, Y. N. (2012). China in 2011: Anger, Political Consciousness, Anxiety, and Uncertainty. Asian Survey, 1, 28-41. https://doi.org/10.1525/as.2012.52.1.28

Zheng, Y. N. (2013). China in 2012: Troubled Elite, Frustrated Society. Asian Survey, 1, 162-175. https://doi.org/10.1525/as.2013.53.1.162 